\title{
DYNAMIC CHARACTERISTICS AND STABILITY OF FLEXIBLE RISER UNDER CONSIDERATION OF NON-UNIFORM TENSION AND INTERNAL FLOW
}

\author{
Dingbang Yan \\ Institute of Mechanics, Chinese Academy of Sciences \\ School of Engineering Science, University of Chinese \\ Academy of Sciences, Beijing, China \\ Yilun Li \\ School of Aeronautics Sciences and Engineering, \\ Beijing University of Aeronautics and Astronautics \\ Beijing, China \\ Min Li \\ School of Aeronautics Sciences and Engineering, \\ Beijing University of Aeronautics and Astronautics \\ Beijing, China
}

\author{
Shuangxi Guo\# \\ Institute of Mechanics, Chinese Academy of Sciences \\ School of Engineering Science, University of Chinese \\ Academy of Sciences, Beijing, China \\ Jixiang Song \\ Institute of Mechanics, Chinese Academy of Sciences \\ School of Engineering Science, University of Chinese \\ Academy of Sciences, Beijing, China \\ Weimin Chen ${ }^{\star 1}$ \\ Institute of Mechanics, Chinese Academy of Sciences \\ School of Engineering Science, University of Chinese \\ Academy of Sciences, Beijing, China
}

\section{ABSTRACT}

As oil and gas industry is developing towards deeper ocean area, the length and flexibility of ocean risers become larger, which may induce larger-amplitude displacement of flexible riser response due to lower structural stiffness against environmental and operational loads. Moreover, suffering not only the external fluid loads coming from environmental ocean wave and current, these risers also convey internal flow. In other words, the dynamic characteristics and response of the flowconveying riser face great challenge, such as bucking, divergence and flutter, because of the fluid-solid coupling of the internal hydrodynamics and riser structural dynamics.

In this study the dynamic characteristics and stability of a flexible riser, under consideration of its internal flow and, particularly, non-uniform axial tension, are examined through our FEM numerical simulations. First, the governing equations and FEM models of a flexible riser with axially-varying tension and internal flow are developed. Then the dynamic characteristics, including the coupled frequency and modal shape, are presented, as considering the speed of internal speed changes. At last, the dynamic response and corresponding stability behaviors are discussed and compared with the cases of riser with uniform tension. Our FEM results show that the stability and response are quite different from riser with uniform tension. And, the time-spatial evolution of riser displacement exhibit a strong wave propagation phenomenon where travelling wave are observed.

Keywords: Fluid-conveying riser; Non-uniform tension; dynamic characteristics and stability; Fluid-solid coupling

$\begin{array}{cl}\text { NOMENCLATURE } \\ x & \text { longitudinal coordinate } \\ y & \text { transverse displacement } \\ L & \text { length of the riser } \\ \mathrm{s} & \text { inner perimeter of riser } \\ E I & \text { bending stiffness } \\ V & \text { flow velocity } \\ m_{f} & \text { mass per unit length with fluid } \\ m_{r} & \text { mass per unit length of riser } \\ g & \text { gravitational acceleration } \\ T & \text { tension } \\ Q & \text { shear force } \\ F & \text { transverse force } \\ \mathcal{M} & \text { bending moment } \\ \Omega & \text { circular frequency of oscillation } \\ t & \text { time } \\ \xi & \text { dimensionless longitudinal coordinate } \\ \eta & \text { dimensionless transverse displacement } \\ \tau & \text { dimensionless time } \\ u & \text { dimensionless velocity } \\ \zeta & \text { dimensionless tension }\end{array}$

\footnotetext{
* Contact author: wmchen@imech.ac.cn

\# These authors contributed equally to this work.
} 


$\begin{array}{ll}\beta & \text { mass ratio } \\ \gamma & \text { dimensionless gravity } \\ \omega & \text { dimensionless circular frequency } \\ M & \text { mass matrix } \\ U & \text { displacement vector } \\ C & \text { damping matrix } \\ K & \text { stiffness matrix }\end{array}$

\section{INTRODUCTION}

The riser and pipeline with internal flow are widely used in marine engineering, nuclear industry and oil exploitation. The dynamics of them is a typical fluid-solid coupling issue, the stability and response of which principally depend on the properties of internal flow and riser structure, such as internal flow velocity, structural bending stiffness, axial tension and mass density. By now, there have been a large number of studies on the stability issue of the risers with internal flow [1-5], where the structural parameters are uniformly distributed along riser length, or riser tension keeps axially-constant. And, few reports have been seen on dynamic response of a riser with internal flow. However, for a flexible riser in deep water, the influence of the structural weight could not be negligible with the increasing structural length. Therefore, structure parameter, e.g. axial tension, would be no longer uniform along axial length. We may say it is more challenging to study the stability, and even, the response of a flexible riser with axially-varying structural parameters.

The dynamic behaviors of riser and pipeline, considered as Euler or Timoshenko beam, with internal flow have been studied fine in history. Early in 1855, Brillouin observed the self-excited vibrations of cantilever pipes. The first published study of dynamic behaviors of the pipes with internal flow was given by Bourrières[1], where the equation of motion was obtained and analyzed carefully to come to a famous conclusion of stability. Considering a riser conveying fluid is not "closed" systems but "open" systems, Benjamin[2] studied the articulated riser via Lagrange method to obtain the instability forms of riser with different boundary conditions and extension of Hamilton's principle that apply to "open" systems. The articulated pipes is conserved structures the major instability form of which is buckling instability, while the cantilever beam is nonconservative structure the major instability form of which is flutter. Holmes[3] has proved that a beam supported at both ends does not have the flutter instability. Gregory and Païdoussis[4-5] tested and verified the flutter instability of cantilever pipes via theory, calculation and experiment. Païdoussis and Issid[6] established the motion equation of normal pipes with internal flow considering the effect of Kelvin-Voigt constitutive law, tension, gravity, etc. Païdoussis and Laithier[7] studied the vibration question of the pipes with internal flow using Timoshenko beam model, by using the variational method to solve the equation of motion, it was found that the shear effect reduces the eigen-frequencies and critical flow velocities of the cantilever pipe. Païdoussis and Laithier[8] established two Hamiltonian expressions of the Timoshenko beam for transportation fluid. Païdoussis, Luu and Laithier[9] studied the dynamic questions of finite length pipes with internal flow by using the Timoshenko beam theory and potential flow theory and proposed a refined mechanics model, it is found that for short risers clamped at both ends, the eigenfrequency increases. Pramila and Laukkanen[10] studied the dynamics and stability of a Timoshenko tube for short fluid transportation using finite element method (FEM), and they obtained similar conclusion with [9]. Chen studied the problems of in-plane[11-12] and outof-plane[13] vibration of curved beams, the results showed that in-plane vibration and out-of-plane vibration are independent. Dai[14] studied the transportation question of the cantilever pipe consisting of two different materials. When a material with greater stiffness is located at the fixed end, its characteristic frequency is greater than that the material with less stiffness is located at the fixed end. Meng[15] studied the dynamic behaviors of marine riser undergoing both internal and external flow using Euler-Bernoulli beam theory and finite element method. Montoya-Hernández[16] studied the dynamic behaviors of multiphase flow with solid, liquid and gas in marine riser transportation, where multiphase flow model is simplified to a homogenous model by using weights method. Dai[17] derived the nonlinear dynamic equation of a riser with both ends under the action of internal and external flow based on the Hamilton's principle and the Galerkin discretization method.

By now, most of the current researches focus on structures with axially-uniform properties. In practices, for a flexible riser in deep water, its structure parameter, e.g. axial tension, is no longer uniform along riser length. And, by know, few reports have been seen on dynamic response, rather than stability problem, of a riser with internal flow. In this study, the dynamic characteristics, i.e. the natural modal shape and frequency along with the dynamic response of a riser with axially-varying tension are examined. As a comparison, the results of a simplified model, a uniform riser, are also calculated. Our numerical results show that the dynamic behaviours, i.e. the modal shapes and dynamic responses are significantly different from the riser with uniform tension.

\section{Models of Fluid Conveying Riser with Axially-Varying Tension}

\subsection{Governing Equation}

The equation of motion of a vertical riser conveying fluid is derived by using differential element method and the Newton's second law. For the fluid element in Fig.1(a), we can obtain the equilibrium equation by using Newton's second law:

$$
\begin{gathered}
-\mathrm{A} \frac{\partial p}{\partial x}-q s+m_{f} g+F \frac{\partial y}{\partial x}=0 \\
\mathrm{~F}+\mathrm{A} \frac{\partial}{\partial x}\left(p \frac{\partial y}{\partial x}\right)+q s \frac{\partial y}{\partial x}+m_{f}\left(\frac{\partial}{\partial t}+V \frac{\partial}{\partial x}\right)^{2} y=0
\end{gathered}
$$

where $y$ is the transverse displacement, $V$ is the flow velocity, $q$ is the shear stress on the internal surface of the riser, $s$ is the inner perimeter of the riser, and $m_{f}$ is the mass of the internal fluid per unit length. Similarly, for the riser element (Fig.1(b)) we have

$$
\frac{\partial T}{\partial x}+q s+m_{r} g-F \frac{\partial y}{\partial x}=0
$$




$$
\begin{gathered}
\frac{\partial Q}{\partial x}+F+\frac{\partial}{\partial x}\left(T \frac{\partial y}{\partial x}\right)+q s \frac{\partial y}{\partial x}-m_{r} \frac{\partial^{2} y}{\partial t^{2}}=0 \\
Q=-\frac{\partial \mathcal{M}}{\partial x}=-E I \frac{\partial^{3} y}{\partial x^{3}}
\end{gathered}
$$

where, $F$ is the transverse force per unit length between riser wall and fluid. $\mathcal{M}$ is the bending moment, and $E I$ is the bending stiffness. $m_{r}$ is the mass of riser body per unit length. Then we can get the governing equation of fluid-solid dynamics of a vertical riser conveying fluid as

$$
\begin{aligned}
& E I \frac{\partial^{4} y}{\partial x^{4}}+\left[m_{f} V^{2}-\left(m_{f}+m_{r}\right) g(\mathrm{~L}-\mathrm{x})\right] \frac{\partial^{2} y}{\partial x^{2}}-2 m_{f} V \frac{\partial^{2} y}{\partial x \partial t} \\
& +\left(m_{f}+m_{r}\right) g \frac{\partial y}{\partial x}+\left(m_{f}+m_{r}\right) \frac{\partial^{2} y}{\partial t^{2}}=0
\end{aligned}
$$

where, $g$ is the gravitational acceleration. By comparison with the equation of motion of a beam with variable tension:

$$
E I \frac{\partial^{4} y}{\partial x^{4}}+T(x) \frac{\partial^{2} y}{\partial x^{2}}+\frac{d T}{d x} \frac{\partial y}{\partial x}+m_{r} \frac{\partial^{2} y}{\partial t^{2}}=0
$$

Here, the second and the fourth term on the left side of Eq.(1), which essentially describe the effect of fluid centrifugal force and fluid\&structural gravity respectively, can be expressed in terms of a axially-varying tension as follow

$$
T(x)=m_{f} V^{2}-\left(m_{f}+m_{r}\right) g(L-x)
$$

where $T(x)$ represents a compressive effect when it is plus, while it represents tension effect when it is minus. We can see that the axial tension $T(x)$ is linearly-varying along the riser length as shown in Fig.2.

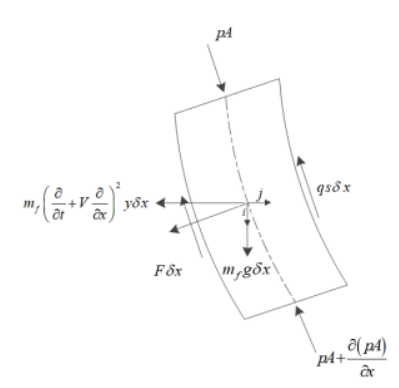

(a)

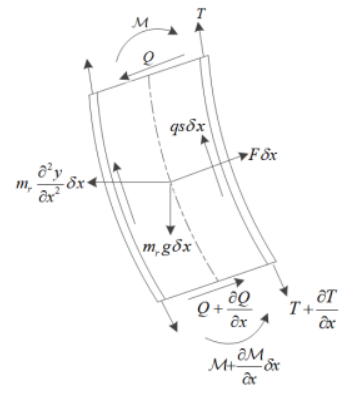

(b)
FIGURE 1: (a) FLUID ELEMENT (b) RISER ELEMENT
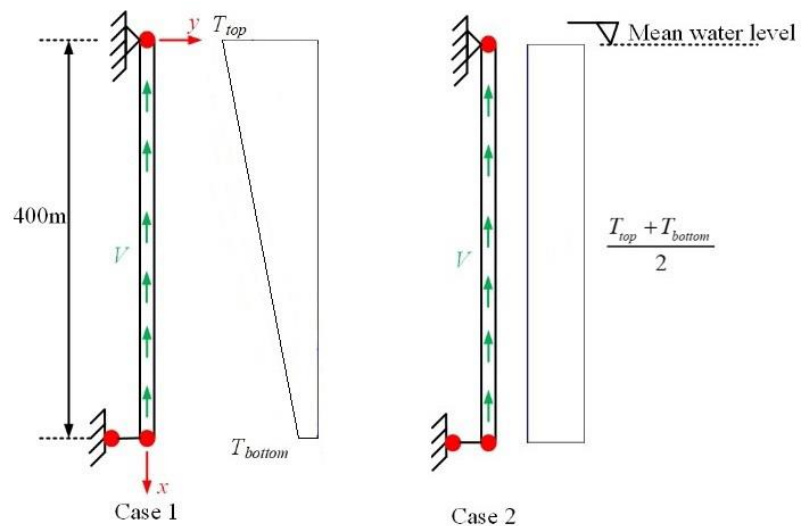

FIGURE 2: SCHEMATIC OF THE FLUID CONVEYING RISER Defining the dimensionless quantities:

$$
\begin{gathered}
\xi=\frac{x}{L}, \eta=\frac{y}{L}, \tau=\left(\frac{E I}{m_{f}+m_{r}}\right)^{\frac{1}{2}} \frac{t}{L^{2}}, u=\left(\frac{m_{f}}{E I}\right)^{\frac{1}{2}} L V \quad \beta=\frac{m_{f}}{m_{f}+m_{r}} \\
\gamma=\frac{\left(m_{f}+m_{r}\right) L^{3}}{E I} g, \zeta=\frac{T L^{2}}{\pi^{2} E I}
\end{gathered}
$$

Equation (6) can be rewritten in the dimensionless form:

$\frac{\partial^{4} \eta}{\partial \xi^{4}}+\left[u^{2}-\gamma(1-\xi)\right] \frac{\partial^{2} \eta}{\partial \xi^{2}}-2 \beta^{\frac{1}{2}} u \frac{\partial^{2} \eta}{\partial \xi \partial \tau}+\gamma \frac{\partial \eta}{\partial \xi}+\frac{\partial^{2} \eta}{\partial \tau^{2}}=0$

Regarding the motion of the riser is a periodic vibration, motions of the form $\eta=Y(\xi) e^{i \omega \tau}$ are considered. The dimensionless frequency $\omega$ can be expressed by the dimensional radian frequency $\Omega$ as

$$
\omega=\left(\frac{m_{f}+m_{r}}{E I}\right)^{\frac{1}{2}} L^{2} \Omega
$$

\subsection{FEM Approach}

The riser is uniformly divided into $n$ two-node Euler beam elements. For representativeness and simplicity, only the translation displacements in $x-y$ plane $\left[u_{i}, v_{i}\right]$ and one rotation degree $\theta_{i}$ around $z$ axis, of per node, are considered. Then the governing equation of the riser with many DOFs (degrees of freedom) can be written as follow:

$$
M \ddot{U}+C \dot{U}+K U=0
$$

where $M$ is the mass matrix including the fluid mass and the structure mass. $C$ is the damping matrix considering the interaction between fluid and structure. $K$ is the stiffness matrix. $U$ is the displacement vector. The displacement vector of the beam element is:

$$
U_{i}=\left[u_{i}, v_{i}, \theta_{i}, u_{i+1}, v_{i+1}, \theta_{i+1}\right] \quad i=1, \ldots, n
$$

In Eq.(1), the third term of the left-side represents the Coriolis force which is usually considered as damping effect to system. The damping matrix of the element is calculated as follows:

$$
C_{e}=2 m_{f} V \cdot N^{\prime} \frac{\partial N}{\partial x}
$$

where $N$ is the shape function matrix of the beam element, and the damping matrix $C$ of the whole structure can be obtained by assembling the damping matrix $C_{e}$ of all elements.

To solve the riser's governing equation (12), an in-house code was implemented[18,19], and the Newmark method is employed here to adjust the distribution of the structural acceleration and velocity in the code. The interpolation functions of the displacement and acceleration are written as:

$$
\begin{aligned}
& \dot{U}_{t+\Delta t}=\dot{U}_{t}+\left[(1-\beta) \ddot{U}_{t}+\beta \ddot{U}_{t+\Delta t}\right] \Delta t \\
& U_{t+\Delta t}=U_{t}+\dot{U}_{t} \Delta t+\left[\left(\frac{1}{2}-\alpha\right) \ddot{U}_{t}+\alpha \ddot{U}_{t+\Delta t}\right] \Delta t^{2}
\end{aligned}
$$

where the values of $\boldsymbol{\alpha}$ and $\boldsymbol{\beta}$ are respectively $1 / 6$ and $1 / 2$ at every time step during the dynamic response.

\subsection{Model Parameters}

In this study the dynamic characteristics, i.e. the natural modal shape and frequency along with the dynamic response of a vertical riser with axially-varying tension are examined under different internal flow velocities. The results of the simplified model (riser with uniform tension) are also calculated as a comparison. The two analyzed models, with different axial tension conditions, are shown in Fig.1. $T_{\text {top }}$ represents the top tension, and $T_{\text {bottom }}$ represents the bottom tension. The risers are simply supported at top and bottom ends, and its main structural and fluid parameters are presented in Table 1. 
The axial tension of the vertical riser consist of the pretension $T_{0}$ and the tension caused by the structural gravity. In Case 1, the actual gravity distribution along riser length is considered, and the axial tension component caused by the riser gravity gradually decreases along the length (x-axis direction) of the riser, as shown in Eq.(8). In case 2, as a simplified model, the part of the axial tension caused by the gravity is assumed as a uniform tension, which equal to the average value the structural gravity, i.e. $0.5 G$. And, $G$ is the gravity of the riser (including internal flow, $\left.G=\left(m_{f}+m_{r}\right) g L\right)$.

TABLE 1. PARAMETERS OF THE RISER

\begin{tabular}{cc}
\hline Parameter & Value \\
\hline Outside diameter & $205.0 \mathrm{~mm}$ \\
Inner diameter & $150.0 \mathrm{~mm}$ \\
Length & $400.0 \mathrm{~m}$ \\
Mass of riser per unit length & $30.0 \mathrm{~kg} / \mathrm{m}$ \\
Tensile stiffness & $1.536 \mathrm{e} 9 \mathrm{~N}$ \\
Mass of fluid per unit length & $17.67 \mathrm{~kg} / \mathrm{m}$ \\
Bending stiffness & $6.19 \mathrm{e} 5 \mathrm{Nm}^{2}$ \\
Pretension $\mathrm{T}_{0}$ & $1,000.0 \mathrm{~N}$ \\
\hline
\end{tabular}

\section{Numerical Results and Discussions}

The dynamic characteristics of a vertical riser with different internal flow velocities is calculated through our model, and the influence of the axially-varying tension on the modal shape of the riser will be analyzed. Furthermore, the responses of the vertical riser caused by the periodic motion of the top-end point are presented, and the influences of the flow velocity and axial tension variation on the displacement response and its temporalspatial evolution of the riser will be studied.

\subsection{Model Verification}

To verify our numerical model, the first mode frequencies of the riser under different axial tension are calculated and compared with the theoretical results. The riser frequencies are shown in Table 2, and the velocities and frequencies are all dimensionless. It can be seen that the calculated frequencies agree well with the theoretical ones (the difference is less than $1.0 \%)$.

TABLE 2. COMPARISON OF THE RISER FREQUENCIES

\begin{tabular}{cccc}
\hline $\begin{array}{c}\text { Dimensionless } \\
\text { tension }\end{array}$ & Numerical & Theoretical & Difference\% \\
\hline 0.0 & 9.870 & 9.870 & 0.000 \\
0.2 & 8.829 & 8.828 & 0.015 \\
0.4 & 7.648 & 7.645 & 0.037 \\
0.6 & 6.247 & 6.242 & 0.082 \\
0.8 & 4.423 & 4.414 & 0.220 \\
\hline
\end{tabular}

\subsection{Inherent Dynamic Characteristics}

Figure 3 shows the plots of the natural frequency versus the internal flow velocity. It is seen that, owing to the axially-varying tension, the frequency becomes smaller than the riser with uniform tension, e.g. by $20.7 \%$ and $18.7 \%$ for the first two modes as $\mathrm{u}=0$. The frequency difference increases with increasing flow velocity. With the increase of the internal flow velocity, the frequency gradually decreases. And the first frequency drops very close to zero, or the riser losses its stability when the dimensionless velocity $\mathrm{u}$ approaches to about 68 . But the frequencies of the uniform axial tension model do not change obviously, see Table 3 . This is mainly because that, with increasing flow velocity, the tension at the bottom end of the riser in Case 1 becomes much smaller than Case 2. In other words, the critical velocity of the riser with axially-varying tension gets smaller, that should be paid careful attention during stability analysis of a riser in deep water.

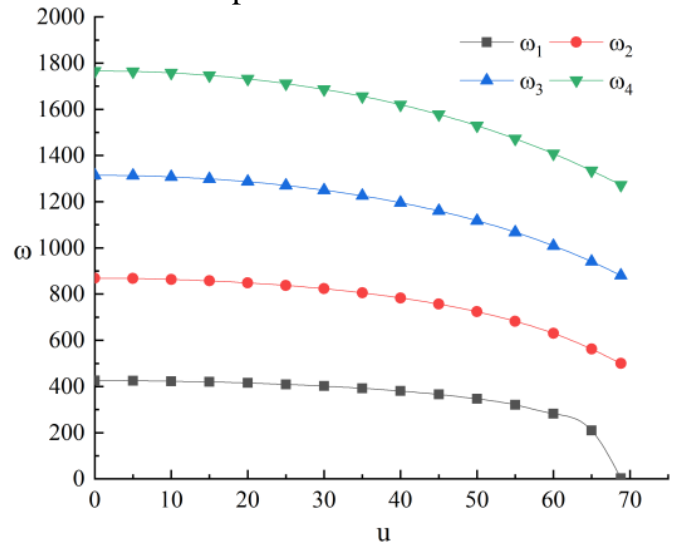

(a)

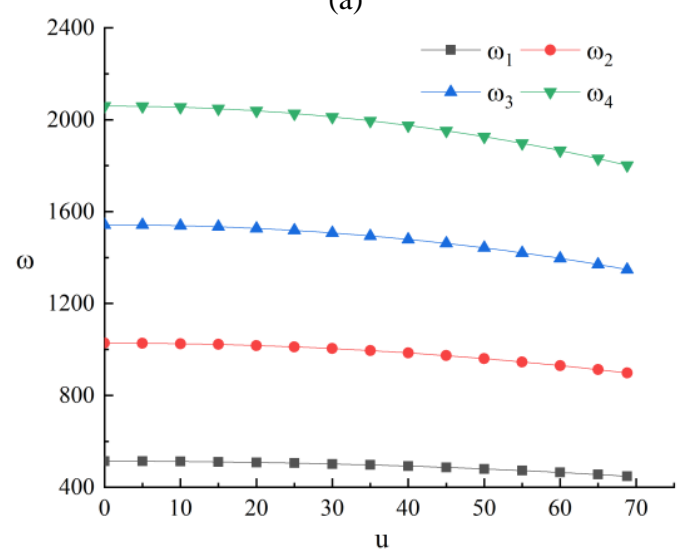

(b)

FIGURE 3: RISER FREQUENCY UNDER DIMENSIONLESS FLOW VELOCITY IN RANGE OF 0-70 (a) CASE 1 (b) CASE 2

The comparisons of the first three modal shapes, at different flow velocities, are shown in Fig.4. Interestingly, the modal shape is no longer symmetric/anti-symmetric to the central point of the riser. In other words, the modal wave length gets smaller while the wave amplitude gets larger, owing to the axiallyvarying tension. And, the maximum modal amplitude moves toward the position with smaller axial tension.

TABLE 3. FREQUENCY OF THE FLUID CONVEYING RISER

\begin{tabular}{ccccccc}
\hline \multirow{2}{*}{$\mathrm{u}$} & \multicolumn{3}{c}{ Case 1 $(\boldsymbol{\omega})$} & \multicolumn{3}{c}{ Case 2 $(\boldsymbol{\omega})$} \\
& Mode 1 & Mode 2 & Mode3 & Mode 1 & Mode 2 & Mode 3 \\
\hline 0 & 425.361 & 868.446 & 1314.352 & 513.537 & 1027.604 & 1542.729 \\
5 & 424.744 & 867.300 & 1312.677 & 513.185 & 1026.898 & 1541.847 \\
10 & 422.892 & 863.685 & 1307.563 & 512.215 & 1024.959 & 1538.849 \\
15 & 419.806 & 857.600 & 1298.922 & 510.539 & 1021.696 & 1533.911 \\
20 & 415.309 & 849.047 & 1286.665 & 508.247 & 1017.023 & 1527.033 \\
25 & 409.313 & 837.673 & 1270.617 & 505.249 & 1011.027 & 1518.127 \\
30 & 401.730 & 823.212 & 1250.337 & 501.545 & 1003.708 & 1507.194 \\
\hline
\end{tabular}




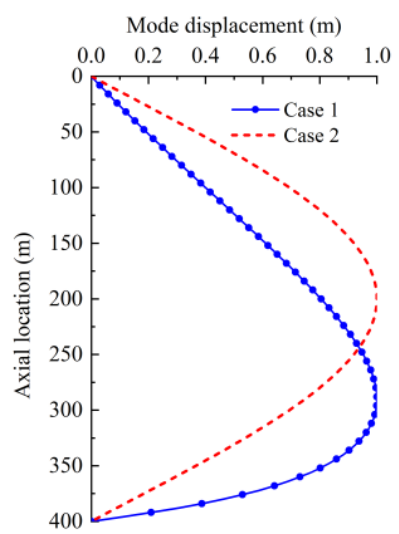

(a)

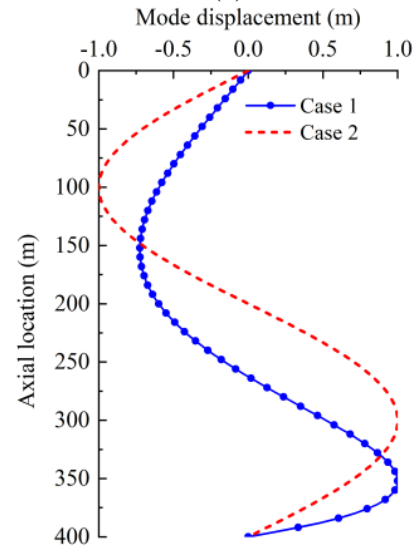

(c)

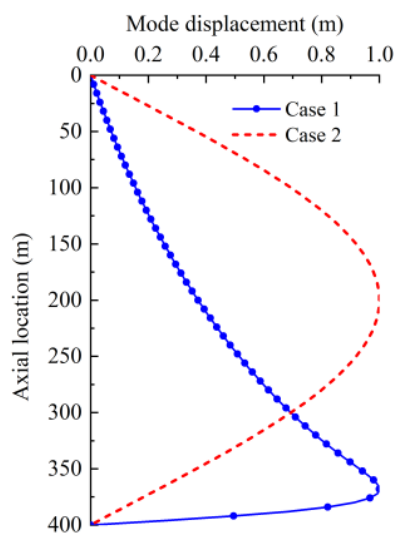

(b)

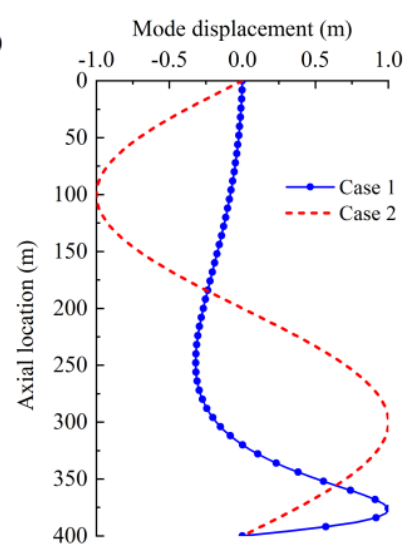

(d)

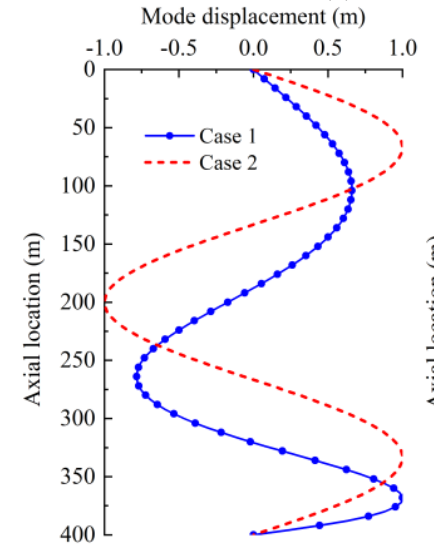

(e)

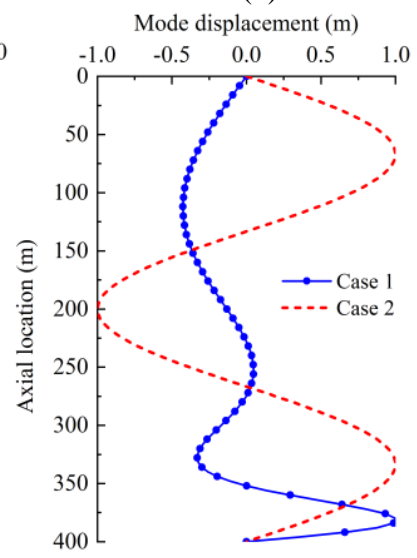

(f)
FIGURE 4: COMPARISON OF THE FIRST THREE MODAL SHAPES (a) THE FIRST MODE AT $u=0$ (b) THE FIRST MODE AT $u=64$ (c) THE SECOND MODE AT $u=0$ (d) THE SECOND MODE AT $u=64$ (e) THE THIRD MODE AT $u=0$ (f) THE THIRD MODE AT $u=64$

To explain the change of modal wave length along riser length, we can observe the expression of natural frequency $\Omega_{i}$ of a riser with axial tension $T$, which is written as

$$
\Omega_{i}=\left(\frac{i \pi}{L}\right)^{2} \sqrt{\frac{E I}{\rho}\left(1-\frac{T L^{2}}{i^{2} \pi^{2} E I}\right)}
$$

So we have the equivalent stiffness $(E I)_{e}$ as:

$$
(E I)_{e}=E I\left(1-\frac{T(x) L^{2}}{i^{2} \pi^{2} E I}\right)
$$

Then we can obtain the corresponding wave velocity

$$
c=\sqrt{(E I)_{e} /\left(m_{r}+m_{f}\right)}
$$

Observing Eq.(17), it is seen that when $T$ is compression, the equivalent stiffness gets smaller, and vice versa. From the topend to bottom-end, the equivalent stiffness of the riser with axially-varying tension decreases because the axial tension gradually gets larger (the compression effect gets smaller). Therefore, the wave velocity gets smaller during propagation along the riser length due to the decreasing equivalent stiffness, and the maximum modal amplitude moves toward the position with smaller axial tension (bottom end).

\subsection{Dynamic Responses}

In this section, the dynamic response of the riser caused by top-end motion is analysed at different flow velocities. The topend frequency is selected as the 3th bending frequency of the riser, and the motion amplitude is $10 \mathrm{~m}$.

For the riser with axially-varying tension, the root mean square (RMS) of displacements under different internal flow velocities are presented in Fig. 5a. It can be seen that with the increase of velocity, the displacement response of the riser increases gradually, because the axial compression caused by internal flow results in a decrease of the riser stiffness. In addition, it can be seen that the maximum displacement occurs near the area close to the bottom-end where the tension is smaller. And, owing to the decreasing tension, the displacement response of the top-end could be amplified during its propagating along riser length.

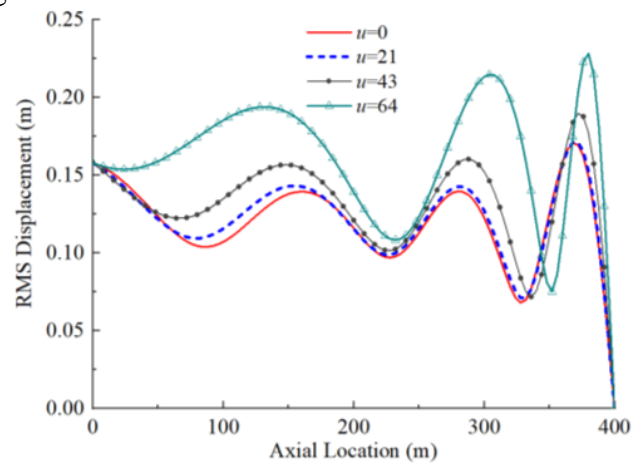

(a)

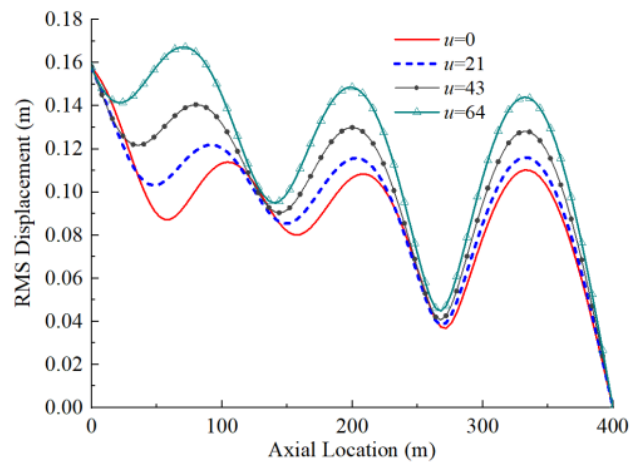

(b)

FIGURE 5: THE RMS CURVE OF RISER DISPLACEMENT WITH DIMENSIONLESS FLOW VELOCITIES $u=0,21,43$ AND 64 (a) CASE 1 (b) CASE 2 
As a comparison, the response of the riser under uniform axial tension is shown in Fig.5b. On the contrary, the response of the riser with uniform axial tension gradually decreases along the length of the riser.

Considering axially-varying tension, the temporal and spatial evolutions of the riser displacement are presented in Fig.6. Obvious wave propagation characteristics can be seen in Fig.6. Generally, there exists three standing waves over the whole length, and the wavelength gets significantly smaller during propagation along the riser length. With the increase of internal flow velocity, the wavelength of the first standing wave increases, and the peak position of the third wave moves down to the bottom-end. This phenomenon is consistent with the RMS result shown in Fig.5a.

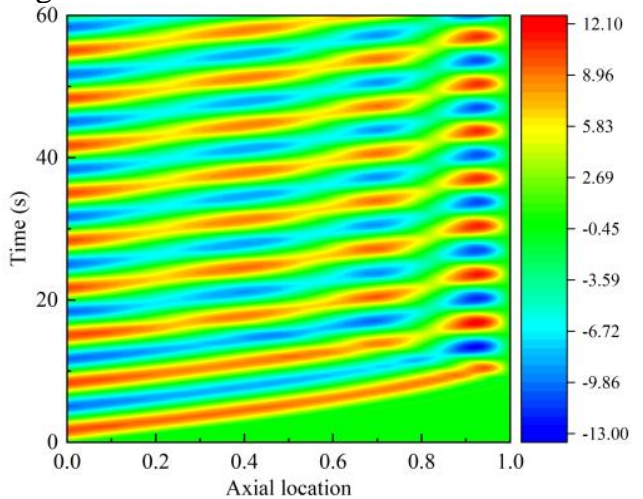

(a)

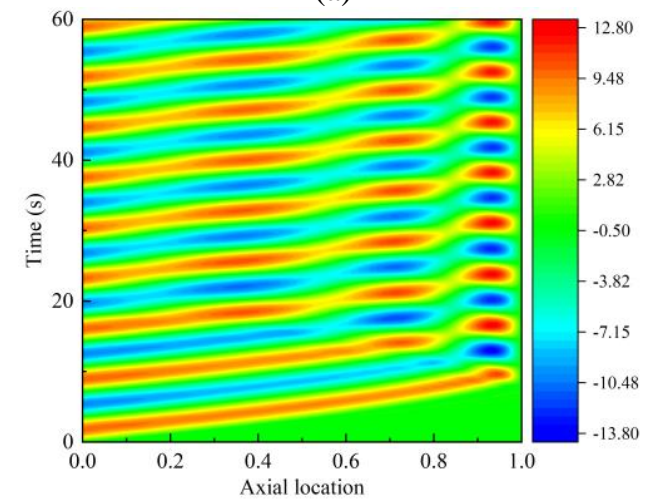

(b)

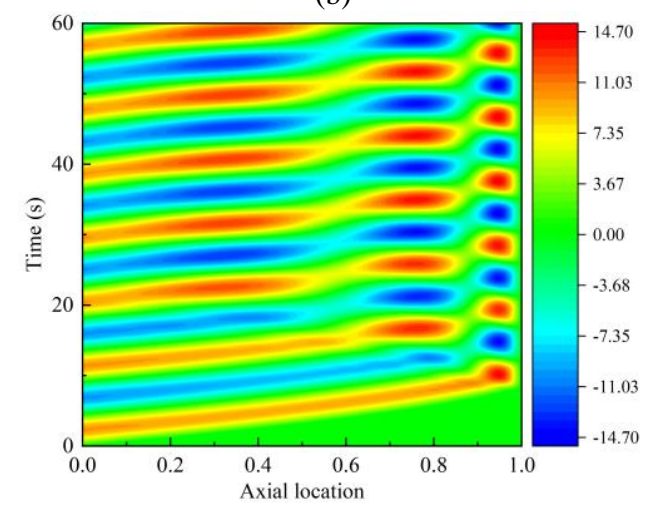

(c)

FIGURE 6: TEMPORAL-SPATIAL EVOLUTION OF RISER DISPLACEMENT FOR CASE 1 (a) $u=0$ (b) $u=43$ (c) $u=64$
As a comparison, the wavelength and position have no obvious change for case of the riser with uniform tension, as shown in Fig.7. It is also noted that the displacement amplitude is larger, up to $19.7 \%$, than the uniform tension riser owing to the axially-varying tension.

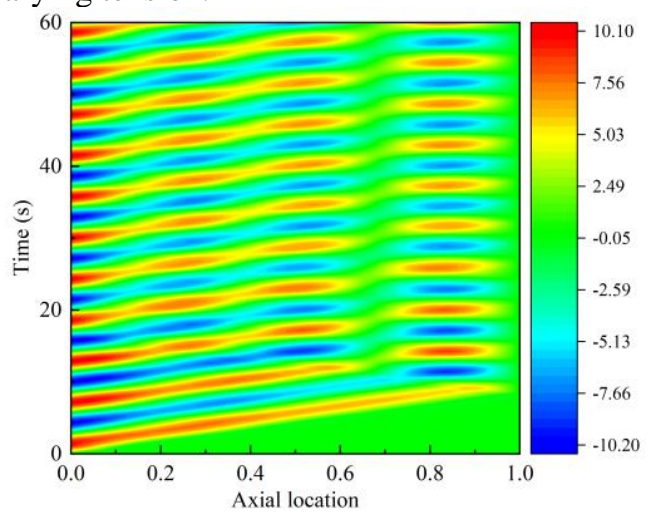

(a)

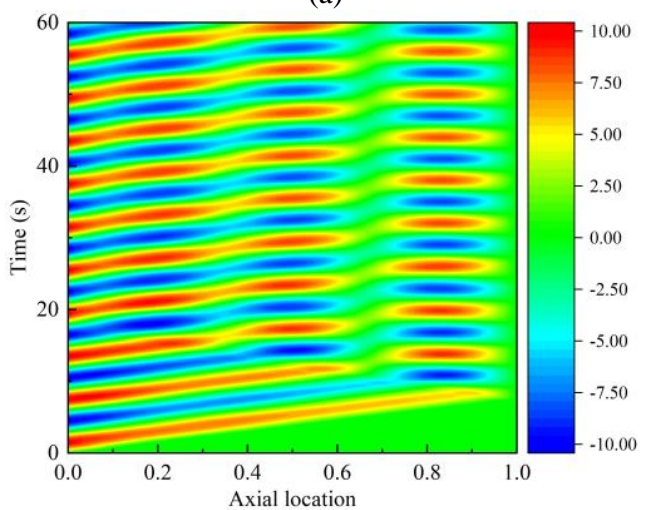

(b)

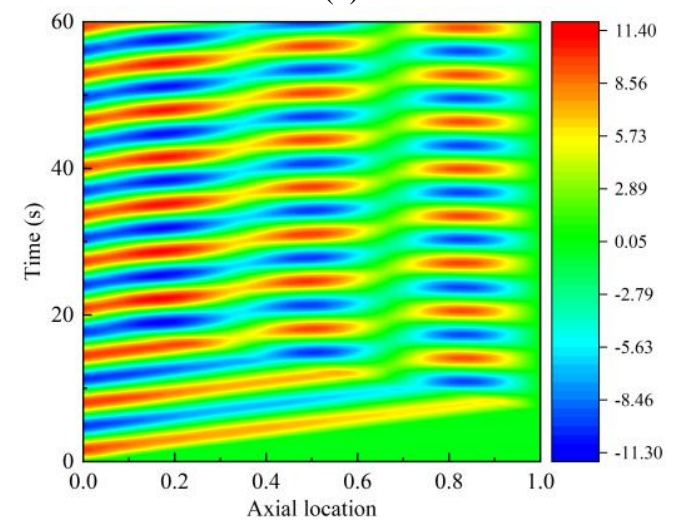

(c)

FIGURE 7: TEMPORAL-SPATIAL EVOLUTION OF RISER DISPLACEMENT FOR CASE 2 (a) $u=0$ (b) $u=43$ (c) $u=64$

\section{CONCLUSION}

In this study the dynamic characteristics, stability and response of a fluid conveying riser, under consideration of nonuniform axial tension, are examined through our FEM numerical simulations. The influences of axially-varying tension on the frequency, modal shape and dynamic response are presented. Our numerical results show that: 
The non-uniform tension has significant impacts on the dynamic characteristics and response of the riser. Owing to the axially-varying tension, the frequency is smaller than the riser with uniform tension, e.g. by $20.7 \%$ and $18.7 \%$ for the first two modes as $\mathrm{u}=0$. The modal wave length gets smaller while the wave amplitude gets larger, and the maximum modal amplitude moves toward the position with smaller axial tension. The critical velocity of the riser with axially-varying tension gets smaller, that should be paid careful attention during stability analysis of a riser in deep water. The displacement response of the top-end could be amplified during its propagating along riser length. The maximum displacement occurs near the area close to the bottom-end, and the displacement amplitude is larger, up to $19.7 \%$, than the uniform tension model.

\section{ACKNOWLEDGEMENTS}

The authors of this paper would like to thank the financial supports provided by the Strategic Priority Research Programme of the Chinese Academy of Sciences (Grant No. XDA22000000).

\section{REFERENCES}

[1] Bourrières, François-Joseph, and Henri Bénard. Sur un phénomène d'oscillation auto-entretenue en mécanique des fluides reels. Publications Scientifiques et Techniques du M inistère de l'Air,1939,No.147.

[2] Benjamin T B. Dynamics of a System of Articulated Pipes Conveying Fluid. I. Theory[J]. Proceedings of the Royal Society of London. Series A, Mathematical and Physical Sciences, 1961, 261(1307):457-486.

[3] Holmes, P. J. Pipes Supported at Both Ends Cannot Flutter[J]. Journal of Applied Mechanics, 1978, 45(3):619.

[4] Gregory, R. W, Païdoussis, M. P. Unstable Oscillation of Tubular Cantilevers Conveying Fluid. I. Theory[J]. Proceedings of the Royal Society of London, 293(1435):512-527.

[5] Gregory, R. W, Païdoussis, M. P. Unstable Oscillation of Tubular Cantilevers Conveying Fluid. II. Experiments[J]. Proceedings of the Royal Society of London. Series A, Mathematical and Physical Sciences, 1966, 293(1435):528-542.

[6] Païdoussis. M P, Issid N T. Dynamic stability of pipes conveying fluid[J]. Journal of Sound and Vibration, 1974, 33(3):267-294.
[7] M, P, Païdoussis, et al. Dynamics of Timoshenko Beams Conveying Fluid[J]. Journal of Mechanical Engineering Science, 1976.

[8] Laithier, B. E., and M. P. Païdoussis. The equations of motion of initially stressed Timoshenko tubular beams conveying fluid[J]. Journal of Sound and Vibration, 1981,79(2): 175-195.

[9] Païdoussis. M P, Luu T P, Laithier B E. Dynamics of finitelength tubular beams conveying fluid[J]. Journal of Sound and Vibration, 1986, 106(2):311-331.

[10] Pramila A, Laukkanen J, Liukkonen S. Dynamics and stability of short fluid-conveying Timoshenko element pipes[J]. Journal of Sound and Vibration, 1991, 144(3):421-425.

[11] Chen S S. Vibration and Stability of a Uniformly Curved Tube Conveying Fluid[J]. The Journal of the Acoustical Society of America, 1972, 51(1B):1087.

[12] Chen S S. Flow-induced in-plane instabilities of curved pipes[J]. Nuclear Engineering and Design, 1972, 23(1):29-38.

[13] Chen, S S. Out-of-Plane Vibration and Stability of Curved Tubes Conveying Fluid[J]. Journal of Applied Mechanics, 1973, 40(2):362.

[14] Dai H L, Wang L, Ni Q. Dynamics of a fluid-conveying pipe composed of two different materials[J]. International Journal of Engineering Science, 2013, 73(Complete):67-76.

[15] Meng S , Kajiwara H , Zhang W . Internal flow effect on the cross-flow vortex-induced vibration of a cantilevered pipe discharging fluid[J]. Ocean Engineering, 2017, 137:120-128.

[16] Montoya-Hernandez, D.J, Vazquez-Hernandez, A.O, Cuamatzi R, et al. Natural frequency analysis of a marine riser considering multiphase internal flow behavior[J]. Ocean Engineering, 2014, 92:103-113.

[17] Dai H L, Abdelkefi A, Wang L. Modeling and nonlinear dynamics of fluid-conveying risers under hybrid excitations[J]. International Journal of Engineering Science, 2014, 81:1-14.

[18] Guo S, Li Y, Li M, et al. Dynamic Response Analysis on Flexible Riser With Different Configurations in Deep-Water Based on FEM Simulation[C], ASME 2018, International Conference on Ocean, Offshore and Arctic Engineering. 2018: V005T04A016.

[19] Li Y, Guo S, Kong Y, et al. Non-Linearly Restoring Performance and its Hysteresis Behavior of Dynamic Catenary[C]. ASME2019, International Conference on Ocean, Offshore and Arctic Engineering, 2019 (5A): V05AT04A016. 